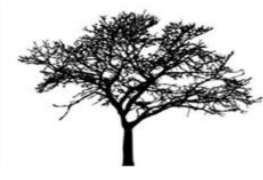

TÜRKIYE'DE KUŞAKLAR ARASINDAKI SIYASI ILETIŞiM ALGILARININ FARKLARI:

KÜLTÜR VE LIDERLIK PERSPEKTIFINDEN BİR DEĞERLENDIRME

\title{
Dr. Bülent ÖZTÜRK*
}

Öz

Insanların iletişim algıları, pek çok farklı faktör tarafından etkilenir ve tayin edilir. Bireysel düzeyde iletişime yön veren faktörler çeşitlilik gösterse de insan gruplarının iletişim algı ve yönelimleri, genel eğilimleri saptanarak tespit edilebilmektedir. Grupların belirgin hassasiyetleri, hayatlarına yön veren temel değerler, değerler sisteminin getirdiği öncelik sırası, ortak deneyimler, temel düşünme stratejileri, yaklaşım biçimleri, yaşadıkları dönemin sosyokültürel özellikleri gibi faktörler onların iletişim algılarını belirler. Siyasal iletişim ise kendine özgü iletişim biçimlerine sahip bir iletişim alanı olarak bu algılardan ayrı ve uzak değildir. İnsan gruplarının iletişim algılarına yön veren faktörler, siyasal iletişim alanında belirleyiciliği yüksek olan önemli bir değişkenler kümesidir.

Kültür, kuşak ayrımları ve liderlik algısı ise alan yazınında iletişime yön veren temel etkenler arasında sıklıkla sayılmaktadır. Bu çerçevede çalışmanın temel hipotezi; X, Y, Z kuşaklarının arasında kültürel farklar bulunduğu ve bu farkların siyasal iletişim bağlamında da farklı algılamalar meydana getirdiğidir. Çalışmada bu ana hipotez çerçevesinde kuşakların siyasal iletişim algıları arasındaki farklarının kültür ve liderlik değişkenleri açısından tespit edilmesi amaçlanmıştır. Bahsi geçen ana amaç ekseninde öncelikle $X, Y$ ve $Z$ kuşaklarının siyasal iletişimlerinin farklı olmasını sağlayan faktörler tespit edilmiştir. Tespit edilen bu temel faktörler etrafında iletişim, liderlik, kültür açısından kuşaklara yön veren temel dinamikler belirlenmiştir. Literatür taraması yöntemi kullanılarak saptanan kuşaklar arası siyasal iletişim algı farklııklarının ardından söz konusu farklııklar, kültür ve liderlik perspektifinden ele alınmıştır. Araştırma sonucunda kuşakların farklı iletişim stratejileri kullandıkları, her bir kuşağın kendine özgü kültürel dinamikleri olduğu ve liderlik yaklaşımlarının kuşaklara göre çok belirgin farklılıklar gösterdiği tespit edilmiştir. Liderlik, kültür ve iletişim gibi üç ana değişkenin kuşaklara göre farklııılar göstermesinin siyasal iletişim algısına da yansıdığı saptanmıştır. Elde edilen bu bulgular, araştırmanın sonuç bölümünde değerlendirilmiş ve önerilerde bulunulmuştur.

Anahtar Kelimeler: Siyasal İletişim, İletişim, Halkla Illişkiler.

\section{DIFFERENCES OF POLITICAL COMMUNICATION PERCEPTIONS BETWEEN GENERATIONS IN TURKEY: AN ASSESSMENT FROM THE CULTURE AND LEADERSHIPPERSPECTIVE}

\begin{abstract}
People's communication perceptions are influenced and determined by many different factors. Although the factors that direct communication at the individual level vary, the perception and orientation of communication in human groups can be understood by determining their general tendencies. Factors such as the specific sensitivities of groups, the basic values that shape their lives, the order of priority brought by the value system, common experiences, basic thinking strategies, approaches, and sociocultural characteristics of the period they live in determine their communication perceptions. Political communication, on the other hand, as a communication field with its own communication styles, is not separate and far from these perceptions. The factors that direct the communication perception of human groups
\end{abstract}

\footnotetext{
•İçişleri Bakanlığı, 0000-0001-5989-4721, bulentozturk3@gmail.com
} 
are an important set of variables that are highly determinative in the field of political communication.

Culture, generational distinctions and leadership perception are frequently counted among the main factors that guide communication in the literature. In this context: The main hypothesis of the study is that there are cultural differences between the $\mathrm{X}, \mathrm{Y}$ and $\mathrm{Z}$ generations and these differences create different perceptions in the context of political communication. In this study, within the framework of this main hypothesis, it is aimed to determine the differences between the political communication perceptions of generations in terms of culture and leadership variables. In line with this main purpose, first, the factors that differentiate political communication of the $\mathrm{X}, \mathrm{Y}$ and $\mathrm{Z}$ generations determined. Around these basic factors, the basic dynamics which shape generations in terms of communication, leadership and culture have been determined. After the differences in perception of political communication between generations are determined, using the literature review method, these differences are discussed from the perspective of culture and leadership. In result of the research, it is concluded that generations use different communication strategies, each generation has its own cultural dynamics, and leadership approaches differ significantly from generations. It is concluded that the differences between generations in terms of three main variables such as leadership, culture and communication are reflected in the perception of political communication. These findings obtained are evaluated in the conclusion part of the research and recommendations are made.

Keywords: Political Communication, Communication, Public Relations.

\section{Giriş}

Siyasal iletişim, en yalın biçimde "günlük hayatın her alanında karşımıza çıkan siyasal iletişim aktörlerinin birbirleriyle yürüttükleri söylemlerinin değiş-tokuşu" (Ayhün, 2013:93-112) şeklinde ifade edilebilir. Siyasal iletişim hayatın her alanında etkilidir ve hayatın her alanı siyasal iletişimin kapsama alanına dâhildir. Siyasal iletişim öz itibariyle bir iletişim biçimidir ve siyasal iletişime yön ve şekil veren, etkileyen faktörler bulunur. Kültür ve liderlik ise siyasal iletişime yön veren en temel dinamiklerden ikisidir. Çünkü bu iki olgu bireylerin yaşam biçimlerini, düşünme biçimlerini, temel değerlerini ve değerler sistemini tayin ederler. Bireyler farkında olmaksızın bu iki olgu ekseninde tüm yaşamlarına ve düşünsel süreçlerine yön verirler. Gerek kültür gerekse liderlik her dönem değişerek kendini yenileyen canlı olgulardır. Bu nedenle farklı zaman dilimlerinde yaşayan insanların temel değer yargıları, düşünme biçimleri ve hayat stilleri; aynı coğrafyada hatta aynı ailede yaşasalar dahi birbirinden farklıdır. Kuşakların kültürel iletişim tutum ve özellikleri birkaç farklı açıdan ele alınabilir. Açıklık, kapalııı, doğrudan-dolaylı gibi farklı özellikler bakımından kültürler ve kuşaklar kıyaslanabilir. En temel ve genel geçer şekilde kullanılan, kültürlerin iletişim profilini analiz eden yaklaşımlardan biri Edward Hall (1987) tarafından ortaya konulan "Yüksek BağlamDüşük Bağlam" kuramıdır. Bir ok üzerinde yüksekten düşüğe kültürlerin iletişim bağlamlarını inceleyen kuram (Tekin, 2015), çalışma kapsamında kuşakların kültürel iletişim değerlerine uyarlanmıştır. Kuramda kullanılan bağlam, "bir olayın anlamı ile ayrılmaz bağlı olan olayı çevreleyen bilgidir. Kültürlerine bağlı olarak olaylar ve bağlam, anlam üretmek için birleştirilmiş olup böylece dünyadaki kültürler yüksek bağlamdan düşük bağlama kadar ölçek üzerinde karşılaştırılma imkânına sahip olmaktadır" (Hall, 1990) şeklinde ifade edilir. Başka bir deyişle bağlam, iletişimin olduğu bütünlüğü, şartları ve durumu ifade etmekte iken iletişimde bağlam bir ilişkinin, bir faaliyetin olduğu 
şartları, örgütlü yer ve zamandaki durumu ifade etmektedir (Mucevher, Akçakanat, Demirgil, 2017). Kuşakların siyasal iletişim algıları arasındaki farklar, Edward Hall (1987) tarafından 1987 yıında ortaya konulan Yüksek Bağlam-Düşük Bağlam kuramı üzerinden çözümlenecek olmakla birlikte bu kuramda; $X$ kuşağının siyasette etkin olduğu, $Y$ kuşağının en büyüğünün 7 yaşında olduğu, $Z$ kuşağının ise henüz doğmadığı bir dönemde geliştirilmiş olduğu unutulmamalıdır. Bu kronolojik duruma rağmen ve bir anakronik hata yapmamak amacıyla bu kuramın günümüz siyasal iletişim algıları bağlamında halen geçerli olduğunu söylemek mümkündür.

Alan yazınında 1965-1979 yılları arasında doğanlar, X kuşağı olarak adlandırılmaktadır ve bu kuşağı resmeden kendine has özellikler bulunur (Morsümbül, 2014). 1980-1999 yılları arasında doğanlar $Y$ kuşağı olarak sınıflandırııı ve tıpkı X kuşağı gibi bu kuşağı da diğer insan gruplarından ayıran temel profil özellikleri bulunur (Gümüş, 2009). 2000 yılı ve sonrası doğumlu olanlar ise Z kuşağı olarak adlandırımaktadır (Dursun ve Eriş, 2018). Günümüzde yaşayan ve en büyüğü henüz genç yetişkin çağında olan bu bireyler bugüne kadar yetişen kuşaklara göre birtakım farklılıklara ve özelliklere sahiplerdir. Kendi içinde resmettiği ana özellikleri ne olursa olsun kuşaklar; sahip oldukları temel yargılar, düşünme biçimleri, yaşam stilleri, yetenekleri, yaklaşımları ve değerleri gibi esas konularda birbirinden net biçimde farklılık gösterdiklerinden sınıflandırmaya tabi tutulurlar. Bu farklılıkları belirleyen çok sayıda ve karmaşık faktörler vardır ancak çalışmanın konusu gereği kuşakları sınıflandırmaya iten faktörlere yer verilmemiştir. Çalışmanın temel amacı ekseninde esas üzerinde durulması gereken mesele; kuşakların hangi özelliklerine göre siyasal iletişim algılarında farklılıklar bulunduğu ve bu farklııılar çerçevesinde kültür ve liderlik kavramlarının, denklemin neresinde yer almak suretiyle siyasal iletişime yön verdiğidir. Çalışma kapsamında bu ana husus üzerinde durularak kuşakların temel kültürel ve liderlik özellikleri etrafında siyasal iletişim algı ve farkılıkları ortaya konulmaya çalışılmıştır.

Kuşakların temel kültürel ve liderlik özellikleri etrafında siyasal iletişim algı ve farklılıkları çalışmanın odak noktası iken dünyanın yedi ayrı kıtasında farklı coğrafyalarda yer alan, farklı kültürel, sosyal ve siyasal hayatlara sahip olan ülkelerde dahi siyasal iletişim faaliyetlerinin benzeşmesi dikkat çekicidir. Bu konuda Oktay (2002:25) farklı seçim sistemleri, farklı siyasal ve kültürel yapılar ve farklı tarihsel geçmişlerine rağmen hemen hemen tüm ülkelerdeki siyasal iletişim uygulamalarında, medya teknolojilerinin gelişmesiyle birlikte "siyasetin Amerikanlaşması" sürecine girdiğinin görüldüğünü ifade etmektedir. Durum bu yönde ilerlese dahi böyle bir süreçte ortaya konulan farkların siyasal iletişim faaliyetlerinde değişimlere ve yeni yaklaşımlara sebep olması beklenmektedir.

\section{Kuşakların Siyasal İletişim Algıları ve Bu Algılara Yön Veren Faktörler}

İnsan nüfusunun kuşaklara göre ayrılması yer yer riskli olsa da özellikle modern dönemlerde yaşam içindeki yenilenmenin ve değişimin hızı olması; toplumların, grupların ve belli dönemdeki insanların belirgin farklılıklar ve diğer insanlara göre ayırt edici özellikler taşımaları sonucunu doğurmuştur. Böyle bir gerçeklik çerçevesinde insanların yaş, yaşanılan dönem, ayırt edici profil özellikleri gibi niteliklere göre ayrıması belli insan gruplarını tanımlamada, tanımada, anlamada ve değerlendirmede 
oldukça yardımcı olmaktadır. Yapılan araştırmalar kişisel özellikler, tutum ve davranışlar açısından kuşaklar arasında farklılıklar bulunduğunu göstermektedir (Twenge, Campbell, 2008: 314).

Kuşaklar ile ilgili çalışmalar ekonomi, demografi, siyaset bilimi, klinik psikoloji ve sosyoloji gibi farklı bilimsel alanlarda elli yıldan fazla zamandır yürütülmektedir (Alwin ve McCammon, 2007: 219). Çalışmanın konusu X, Y ve Z kuşaklarına odaklanmış olsa da nesillerin özelliklerine göre gruplanması yalnızca bu kuşaklarla sınırı değildir: Bebek Patlaması Kuşağı (Baby Boomers; 1946 - 1964 arası doğanlar), X Kuşağı (Gen X; 1965 - 1980 arası doğanlar), Y kuşağı (Gen Me, Gen Y ve Gen N; 1980 - 2000 arasında doğanlar), Z Kuşağı (iGen ve Kuşak I; 2000 yılı ve sonrasında doğanlar) şeklindedir (Twenge vd., 2010: 1130).

$X$ kuşağından başlamak üzere günümüze yön veren insanlar ve değerler $X, Y$ ve Z kuşaklarıdır. 1965 yılı X kuşağının alt sınırıdır (Arslan ve Polat, 2016) ve günümüzde yetişkinler, genç yetişkinler ve çocuk/ergen insan grupları ağırlıklı olarak $X$, $Y$ ve $Z$ kuşağındandır. Bu bağlamda siyasal iletişime konu insan gruplarının taşıdıkları profil özellikleri bakımından incelenmesi; iletişim, liderlik, kültür gibi ana dinamiklerinin bilinmesi çalışma ve siyasal iletişim açısından oldukça önemlidir.

$X$ kuşağının en belirgin profil özellikleri disiplin, görev odaklı olma, geleneklere bağılık gibi klasik denilebilecek niteliklerle karakterizedir. İletişim konusunda ise $X$ kuşağı, iş iletişim becerilerinin gelişkinliğiyle tasvir edilir. İş iletişim becerisi, yeni bir iş bulma ve iş çevresi edinme gibi özelliklerin gelişkin olmasını sağlar. İş iletişim becerileri konusunda yüksek yetiye sahip olan $X$ kuşağı; teknoloji, iletişim teknolojileri, bilgi gibi konularda ise gelişmiş yeteneklere sahip değildir. E-posta ve çevrim içi iş arama gibi basit işlemler için teknolojiyi kullanan bu bireyler genel olarak özgüveni yüksek, aile odaklı, eğlenmeyi seven, risk alabilen, açık görüşlü niteliklerde bir profil çizerler (Karaca, 2012:162). Özgüven, çözüm üretme, ağır sorumluluklar alabilme, iş çevresi geliştirme gibi konularda üstün yeteneklere sahip olan $X$ kuşağı, bilgi ve teknoloji konusunda $Y$ ve $Z$ kuşaklarına görece oldukça geridedir. Örneğin $X$ kuşağından bir birey yalnızca işi olduğu için çevrim içi olup işini halledip çevrim dışı olurken, $Y$ ve $Z$ kuşağından bireyler çevrim içi ve çevrim dışı olarak insanlarla sürekli iletişim halinde kalırlar (Kocasavaş, 2010:151-160).

Y kuşağı ise; sabırsız, iddialı, hızlı düşünebilen, hedef odaklı, özgürlüklerine düşkün, teknolojiye tutkun, otoriteye meydan okumayı seven, sorgulayan, az zamanda iyi iş çıkarmaya odaklı olan, kendilerini seven, güvenen, değer veren, bireysel tavır sergileyen, yüksek performans gösteren, kendi işlerini yapmayı isteyen, iş hayatından beklentileri yüksek olan, sorumluluk almaktan hoşlanan, çalışma arkadaşlarına göre daha hızlı ve daha verimli çalışmayı hedefleyen, sürekli öğrenmeye açık olan, adaptasyon becerileri yüksek olan, arkadaşlarının tavsiyelerine ve paylaşımlarına duyarlı olan, hayatı online yaşayan, alışverişten önce bloglar ve online sözlükler aracılığıyla sosyal medyayı takip eden, online alışverişi aktif olarak kullanan, hayatlarını sosyal medya kanallarında paylaşmayı seven, sanal görüşmeyi tercih eden ve esneklik, özgürlük ve 
bireysel karar alma eğilimleriyle önceki kuşaklardan farklı (Göktaş ve Çarıkçı, 2015:7-33) özellikleriyle karakterize bir kuşaktır.

Bahsi geçen özellikler çerçevesinde $Y$ kuşağı medya ve iletişim alanları öncelikli olmak üzere pek çok alanı yeniden tasarlamıştır. Hobiler, sosyalleşme ve kişisel zamanlar bu kuşağın en çok talep gösterdiği alanlardır ve buna bağlı olarak gazeteler yerine temalı dergileri, fili kitaplar yerine e-kitapları, kütüphaneler yerine dijital veri tabanlarını tercih etmektedirler. Büyüdükleri dönemin en etkin kitle iletişim aracının çok kanallı televizyonlar ve internet olması ise bu kuşağı akıllı, özgürlüğüne düşkün, teknoloji tutkunu ve iletişimi kuvvetli kişilere dönüştürmüştür. Ayrıca $Y$ kuşağı, vaktinin büyük kısmını medya ve iletişim teknolojilerine harcamaktadır. Bir önceki kuşaktan devreden özelliklerle birlikte $Y$ kuşağı hem yüz yüze hem sanal iletişimlerde oldukça yeteneklidir (Ay ve Çağlar, 2019:943-963). İletişim teknolojilerindeki bu hâkimiyetleri, iş yaşamında teknolojiyi aktif kullanmak ve görevler başarmak yetilerini açığa çıkarmıştır. Otokratik yönetim anlayışını esnek örgüt yapıları ve uzmanlığa göre yetkiye dönüştürenler, Y kuşağı bireyleri olmuştur (Bakiş, 2017:97-105). Y kuşağı, taşıdığı bu ilginç ve sentez nitelikler çerçevesinde özellikle Türkiye gibi ülkelerde arada kalmışlık, kimlik bunalımı yaşamak, başarısız olmak gibi gerekçelerle sıkça eleştirilmektedir. $Y$ kuşağı; nitelikleri, doğduğu ve büyüdüğü dönemler, etkinlikleri ve insan nesli içinde işlevleri ekseninde profesyonel bir perspektifle ele alındığında değişimi başlatan nesildir. Dünyanın ve bilginin evrim geçirdiği eşikte yer almaları bunalım, arada sıkışmışlık gibi eleştirilere maruz kalmalarına neden olsa da bu kuşak, esas itibariyle evirilmenin köprüsüdür. Bu nedenle anlaşılamamaları, diğer kuşaklardan daha yoğun kuşak çatışması yaşamaları, köprü işlevlerinin yanlış yorumlanması gibi eleştirilere muhatap olmaları normaldir (Amarat, Durmuş, Şahin ve Güleryüz, 2017). Özellikle bilinen alanları yeniden tasarlamaları ve otoriteye meydan okuyarak özgürleşmeleri, eleştirilerin şiddetini artırmaktadır.

Z kuşağının ise belirleyici profil özellikleri alan yazınında şu şekilde yer almaktadır: Korumacı yapıda ebeveynlere sahip olan, iletişim aracı olarak e-postayı tanımayıp bunun yerine sosyal ağlar ve mobil teknolojilerle iletişim kurmayı tercih eden, daha eğitimli, bireysel ve bağımsız olan, kendilerine olan özgüvenlerinin yüksek olması sayesinde daha rahat ve açık iletişim kurabilen, kendi istek ve amaçlarının farkında olan, amaçları doğrultusunda yaşayan, yaşamda her şeyin mümkün olduğuna inanan, çevrelerinde ve dünyada olan gelişmelerin farkında olan bir kuşaktır. Yani iletişim açısından $Z$ kuşağı, mobil teknolojilerle iletişim kurmayı tercih etmekte ve açık iletişimde bulunmaktadır. Twenge (2018:22) bu nesli 'internetle büyüyen ve internet öncesini hatırlamayan nesil', 'I-nesli' ve dijital çağda doğmaları sebebiyle 'dijital yerli' (Z kuşağı) şeklinde tanımlamaktadır.

Z kuşağının diğer kuşaklara göre en büyük farkı, internetin ve teknolojinin içinde doğmuş olmalarıdır. Bilindiği gibi internet, farklı bir bilinç getirirken algılama, düşünme, öğrenme ve farkındalık biçimini değiştiren bir etki taşımaktadır (Arıcak, 2015:15). Bu etkinin kuşak üzerinde de yansıması görülebilmektedir. "Türkiye nüfusunun \%24'ünü oluşturan Z kuşağı, Avrupa Birliği ülkeleri arasında birinci sırada yer almaktadır” (Temir:2020). 
Bireyselliğe önem veren, en yeni iletişim araçlarını kullanan, iş arkadaşlarıyla dost olmayı tercih eden, yeniliğe açık, haberleşmek için eposta yerine sosyal medyayı kullanan, arkadaşlık ilişkilerini ise ağırlıklı olarak Facebook üzerinden yürüten, teknoloji bağımlısı ya da tutkunu olmayıp teknolojiyi doğal yaşam standardı olarak algılayan bir kuşaktır. Temel değerleri; öğrenmek, paylaşmak ve üretmektir (Mengi, 2012).

$Z$ kuşağına mensup bireylerin yaşça en büyükleri bile günümüzde henüz genç yetişkin dönemindedir. Yetişkinliğe henüz erişen bir Z kuşağı olmadığı için Z kuşağının henüz yerleşik karakterinden bahsetmek yanlış olacaktır. 20 yıldır çizdikleri kişilik profilleri açıklandığı gibidir. Yetiştikleri dönem gereği de birtakım imkânlara sahiplerdir ancak yetişkinliğe henüz erişmedikleri için bu imkân ve çağın koşullarını iş ve yaşamlarına nasıl uyarlayacakları belirgin değildir. Türkiye'deki kuşaklar arasındaki ayrım ve bunlara ait betimleyici özellikler de dünyanın genel eğiliminden farklı değildir.

Kuşaklar arası bakış açısı, yaşam ve özellik farklııkları yaşamın her alanında belirleyici değişiklikler yaratmaktadır. Kuşakların, özellikle $X$ ve $Y$ kuşaklarının kendilerine özgü ve farklı özelliklerinin neler olduğu yukarıda ele alınmıştır. En önemli husus ise bu özellik ve farklılıkların siyasal iletişime nasıl yön verdiğidir (Mert, 2020). Özellikle 90'lı yıllardan başlamak üzere $X$ kuşağının yetişerek siyasete ve yaşamın diğer alanlarına dâhil olduğu görülür. 1990'lardan günümüze değin yaşanan farklılaşmalar X kuşağının etkileri şeklinde yorumlanabilecektir. $O$ yıllarda yavaşça yaşam alanlarına etki etmeye başlayan $X$ kuşağı, günümüzde en yoğun biçimde siyaset, sanat, ekonomi gibi alanlara yön veren nesildir (Kılıçer, 2019). 90'lı yıllardan bugüne siyasal iletişim alanında yaşanan kırılma noktaları göz önünde bulundurulduğunda; çok kanallı televizyonlarla birlikte televizyonun temel siyasal iletişim araçlarından birine dönüşmesi, siyasal İslam görüşünün siyasi yaşamda yeniden yükselişe geçmesi, darbe ve muhtıra gibi olayların siyasi yaşamdan çekilmesi, Türkiye'nin küresel bir pazar haline gelmesiyle yaşanan imkân bolluğu, bankacılık sistemlerindeki düzen oturtma deneyimleri ve ülkeye malî yük teşkil eden hortumlama vakaları, terör olaylarının kısa bir aradan sonra yükselişe geçmesi, küreselleşmenin etkilerinin kademeli olarak siyasi yaşamda da görülmesi, ülkeler ve kültürler arası artan iletişim ve gelişen teknolojiler $X$ kuşağının yetişkinlik dönemindeki karakterize olaylardır. Türkiye siyaseti ve siyasal iletişim çalışmaları açısından 1990-2020 yılları X kuşağının etkin olduğu yıllar olarak ele alınırsa 2001 ekonomik krizinin siyaset sahnesi üzerindeki etkileriyle başlayan bu zaman diliminin AK Parti'nin kurulması ve iktidar olarak sürdürdüğü siyasal yaşamıyla devam ettiği görülmektedir. 1990 ile 2020 arasındaki 30 yılın en önemli siyasal hareketleri bunlardır. Bu yıllar arasındaki siyasal iletişim çalışmaları, X kuşağının siyasi yaşama yaptığı etkiyi ortaya koymaktadır.

Günümüzde ise $Y$ kuşağına mensup bireylerin çoğunluğu artık yetişkindir ve 2000'li yıllardan başlamak üzere aktif biçimde hayatın belli alanlarına yön vermektedirler. Özellikle sosyal medyanın bir iletişim aracı olarak siyasal iletişim alanına dâhil olması, Y kuşağının siyasal iletişim ve siyaset alanında yarattığı etkilerin fitilini ateşlemektedir. Sosyal medya araçları üzerinden siyasilerle çift yönlü bir iletişim yakalayan $\mathrm{Y}$ kuşağı; siyasi olayları yaşamın ana odak noktası şeklinde görmek yerine siyaseti, yaşamın küçük bir parçası olarak görmektedir. Bu bakış açısındaki ve yaklaşımdaki farklııı, siyasal iletişim çalışmalarına başlangıç düzeyinden itibaren farkı 
bir yön vermektedir. Y kuşağı siyasal iletişimde daha stratejik, kuşkucu, mizahı sıkça iletişime dahil eden, ikna edilmesi zor ve iletişimdeki temel değerleri kompleks nitelik gösteren bir tutum izlemektedir. Siyasal iletişimin yüzyıllardır klasik araçlarına dönüşmüş bulunan ve Türkiye'de neredeyse 80 yıldır siyasal iletişime yön veren inanç söylemleri, ulusçuluk, ekonomik vaatler, uluslararası prestij ve başarı kazandırma söylemleri, millî değer ve duygu yönlendirmeleri, umutlu gelecek tablolarının çizilmesi gibi faktörler $Y$ kuşağının siyasal iletişimde reddettiği ve mizahla yanıt verdiği unsurlardır. $Y$ kuşağı, küreselleşmenin beşiğinde büyümüş bir kuşak olarak küresel yaşam ve küresel iletişim ekseninde düşünen bir nesildir. Bu bağlamlarda millî değerler ve duygular, ulusçuluk, dış prestij gibi siyasal iletişimin kitleleri ortak paydada toplamak amacıyla kullandığı araçlar, $Y$ kuşağının etkin değerlerine hitap etmemektedir. Ulusçuluk yerine dünya vatandaşı olma, dış prestij yerine küresel düzeyde tanınma ve bilinme gibi farklı değerlerle kendilerini tanımladıklarından, günümüzde bu değerler üzerinden kurulan siyasal iletişime ancak mizahla yanıt vermektedirler. Sahip oldukları özgürlükçü ve bireysel yapıları millî değer ve duyguları harekete yön veren güdüler olarak görmek yerine, öz ve kök değerler şeklinde addetmektedir. Bu durum da siyasal iletişimde $Y$ kuşağı kitlesinin hareketine yön veren değerlere hitap edilmemesine neden olmaktadır. Siyasal iletişimde özellikle $Y$ kuşağının siyasi karikatürlerinin sert eleştirilmesi, siyasi mizahlarına tepkiyle yaklaşılması, siyaset algılarının cezalandırılması, medya iletişimine yönelik belli kısıtlar getirilmesi kitleye hitap eden iletişim fırsatlarının yakalanamamasına neden olmaktadır. Mevcut siyasal iletişim çalışmaları $Y$ kuşağının ilgisini cezbetmek ve onlara hitap etmek üzerine yoğunlaşsa da söz konusu yaklaşımlar, $Y$ kuşağının temel yaklaşımından çok farklıdır. Bu ve benzer etmenlere bağlı olarak günümüz siyasal iletişim çalışmaları; $Y$ kuşağını yakalayan bir frekans, ikna eden bir değerler bütünü ve kurulan sağlıklı bir iletişim sonuçlarından çok uzakta durmaktadır.

\section{Kültür ve Liderlik Ekseninde Kuşakların Siyasal İletişim Algıları}

Kuşakların genel olarak yaşam biçimleri, düşünme biçimleri, yaklaşımları, iletişim algıları gibi unsurlarının farklı olmasının yanında liderlik beklentileri ve kültürel değerleri de birbirinden oldukça farklıdır. Bu fark bazı noktalarda öylesine yüksek bir düzeye ulaşmaktadır ki kuşaklar arasında zıtlıklar meydana gelmektedir. X kuşağı, liderlik konusunda geleneksel çizgiyi yakınsamaktadır. Geleneksel yaklaşımda takipçiler liderden; adil, saygııı, açık ve doğrudan liderlik hareketleri beklerler. Y kuşağı ise $X$ kuşağının aksine mesafe ve otoriteden ziyade saygı ve sevecenliğe önem vermektedir. Y kuşağının liderlik beklentileri sıcaklık, sevecenlik, eşit davranış ve tutum ile demokratik yaklaşımdır. $Z$ kuşağının liderlik beklentileri ise $Y$ kuşağınınkine yakınsar özellikler taşımaktadır. Otorite kavramının Z kuşağı için önemini yitireceği (Mengi, 2009: 14) belirtilmektedir. X kuşağı; sonuç odaklı, esnek, doğrudan, öğrenme imkanlarını destekleyen, özgün, enformel ve yetkili liderlik beklentisine sahiptir (Gündoğdu ve Çelik, 2018:46-63). X kuşağı, modern çağın özelliklerini üstünde taşıyan son nesildir ve $Y$ kuşağı bilgi çağının ilk çocuklarıdır. Bu bağlamda $Y$ kuşağının taşıdığı köprü misyonu, liderlik beklentilerine ilişkin olarak dönüştürücü, farklılaştıran, yeniliği tanımlayan, yol gösterici niteliklerde yansımaktadır. Çünkü $Y$ kuşağı, dönüştürücü, yeniliği tanımlayan, eskiyi dönüştüren, öncü bir dönemde doğup büyümüş olduğundan dönemin özelliklerini doğrudan kuşak profilinde taşımaktadır (Demirdağ, 2019). 
X kuşağı gelenekle özdeştir çünkü modern çağın koşul ve imkânlarında doğup büyümüş son kuşaktır. Bu bağlamda liderlik biçim ve beklentileri de katılımcı ve demokratik olmaktan ziyade otokratiktir ve emir-komuta odaklıdır. Y kuşağı ise katılımcı, izleyene odaklı, liderin koçluk yaptığı, demokratik ve dönüştürücü liderlik tarzlarına eğilimlidir (Yörükoğlu, 1991). Z kuşağı henüz iş yaşamında etkin olmadığı için liderlik pozisyonlarına da yükselmemiştir. Doğup büyüdükleri dönemler, mevcut eğilimleri ve tutumları baz alındığında ise esnek, yetkili, açık ve doğrudan liderlik tarzlarına eğilim gösterecekleri öngörülmektedir.

Tablo 1. X ve Y Kuşağının İş Yaşamı Değerleri

\begin{tabular}{|c|c|c|}
\hline $\begin{array}{l}\text { Mesleki Faktörlere Íliş̧kin } \\
\text { Görüşler }\end{array}$ & X Kuşağı & Y Kuşağı \\
\hline Motivasyon & Kendi kendine motive olan & $\begin{array}{l}\text { Yöneticileri iș ve kariyer } \\
\text { hedeflerini belirlediği } \\
\text { zaman motive olan }\end{array}$ \\
\hline Takdir/onaylanma & Övgü, takdir ve ücret & $\begin{array}{c}\text { Tanınmak ve saygı } \\
\text { duyulmaktan hoșlanırlar }\end{array}$ \\
\hline Sadakat & $\begin{array}{c}\text { Örgüt içinde firsatlar varsa } \\
\text { örgüte sadık }\end{array}$ & $\begin{array}{l}\text { Örgütlere daha az sadık ve } \\
\text { șüpheci, } \\
\text { kișisel hedeflerine ulaștığı } \\
\text { sürece sadık ancak firsat } \\
\text { bulamadığında kolaylıkla } \\
\text { örgütten ayrılabilen }\end{array}$ \\
\hline İș-yașam dengesi & Yașamak için çalıșma & $\begin{array}{l}\text { Çalıșmaktan keyif alırken iș } \\
\text { dıșındaki zamanlarına da } \\
\text { oldukça değer veren, } \\
\text { hayattaki en önemli șey iș } \\
\text { değildir düșüncesine sahip }\end{array}$ \\
\hline Teknolojik yönelim & Teknolojiye yatkın & $\begin{array}{c}\text { Yüksek teknolojinin yoğun } \\
\text { kullanıcıları }\end{array}$ \\
\hline $\begin{array}{c}\text { Ödüllere karșı tutum(içsel- } \\
\text { dıșsal) }\end{array}$ & $\begin{array}{c}\text { Ödüllerin kıdem esasına göre } \\
\text { değil liyakat esasına göre } \\
\text { olmasını isterler, } \\
\text { motive olmaları tamamen } \\
\text { paraya bağlı değildir }\end{array}$ & $\begin{array}{l}\text { Finansal olarak akıll, } \\
\text { bireysel gelișime önem } \\
\text { veren, } \\
\text { hem içsel hem de dıșsal } \\
\text { ödülere önem veren }\end{array}$ \\
\hline Değișim & Değișime uyumlu & Değișime meraklı \\
\hline $\begin{array}{l}\text { Bireycilik ya da takım } \\
\text { tercihi }\end{array}$ & $\begin{array}{l}\text { Kendine güvenen ve kendi } \\
\text { kendine yeten, } \\
\text { yalnız calıșmayı tercih eden }\end{array}$ & $\begin{array}{l}\text { Çeșitlilik isteyen ve ekip } \\
\text { çalıșmasına ilgi duyan }\end{array}$ \\
\hline Gözetim ve yönlendirme & $\begin{array}{l}\text { Performanslarına özel olarak } \\
\text { yapıcı geri bildirim bekleyen }\end{array}$ & $\begin{array}{l}\text { Sürekli geri bildirimden } \\
\text { hoșlanan, } \\
\text { her çalısana özel ilgi } \\
\text { gösterilmesini bekleyen }\end{array}$ \\
\hline Kariyer tercihi & $\begin{array}{l}\text { Kidemden ziyade anlik } \\
\text { memnuniyete cevap veren }\end{array}$ & $\begin{array}{c}\text { Kendileri için anlamı olan } \\
\text { bir iși tercih eden, } \\
\text { iși, öncelikli olarak } \\
\text { özgeçmiș olușturmak } \\
\text { maksadıyla gören }\end{array}$ \\
\hline Öğrenme yeteneği & $\begin{array}{c}\text { Eğitim sağlayan ișyerini } \\
\text { tercih eden }\end{array}$ & $\begin{array}{c}\text { Eğitim planlarının } \\
\text { olușturulmasında aktif rol } \\
\text { almak isteyen, } \\
\text { șu ana kadarki en eğitimli } \\
\text { nesil }\end{array}$ \\
\hline
\end{tabular}


Kaynak: Winter, R. P., and Jackson, B. A. (2016).

Kuşakların değişik özellikleri doğrultusunda siyasal iletişim algılarında belirgin farklılıklar olmasıyla birlikte bu durumun farklı liderlik ve siyasi liderliği ortaya çıkarması oldukça doğaldır. Bunların yanında liderlik gibi kültür de kuşaklar tarafından farklı özelliklerle tanımlanan nitelikler içerir. Kuşakların kültürel değerlerindeki farklılık tüm yaşam ve alanlara farklı bir yön verirke, iletişim konusunda da pek çok bilineni değiştirmektedir. Bu bağlamda kuşakların kültür ve iletişim değerlerine bakmak oldukça faydalıdır.

Yüksek bağlam ve düşük bağlamın yer aldığı aralıkta, değişiklik gösteren kültürel iletişim değerleri bulunur. Düşük bağlamda, insanlar mesajları alıcılara doğrudan gönderir, iletişimde açık ve net bir tutum izlenir, iletilmek istenen duygu ve düşünceler mesaja olduğu gibi aktarıır; alıcı, sağlıklı iletişim kurmak amacıyla dış bir faktöre intiyaç duymaz. Batı kültürleriyle özdeşleştirilen bu iletişim türünde açık ve keskin ifadeler kullanıır, direkt söylemler yoğunluktadır, emirden çok öneri verme eğilimi mevcuttur (Robbins, Judge ve Langton, 2013). Yüksek bağlamlı kültürlerde ise ima, dolaylı iletişim ve kapalııı ön plandadır. Gerçekte söylenmek istenenler mesajda açıkça yer almaz; bu nedenle alıcı yalnızca söylenenle değil jest, mimik, ses tonu, imgeler, geçmiş tecrübeler, sessizlik durumları gibi farklı araçlarla mesajı algılamaya çalışır. Çin, Japonya, Hindistan gibi toplulukçu yönü öne çıkan Doğu kültürleri yüksek bağlamda ele alınır (Özgür, 2019).

Kuşakları da bu kültürel bağlamlara genel olarak adapte etmek mümkündür. $X$, $Y$ ve $Z$ kuşaklarının çizdikleri genel profil ve özelliklerinden yola çıkıldığında; $X$ kuşağının görece daha klasik ve geleneksel, $Z$ kuşağının ise görece modern ve marjinal bir profil çizdiği açıktır. Yüksek ve düşük kültür bağlamları, iletişim ve kuşaklar aynı eksende ele alındığında ise kesişim noktalarının kuşakları da modele eklemeye olanak verdiği görülür.

Şekil 1. Yüksek ve Düşük Bağlam Kültürleri Ekseninde Kuşaklar

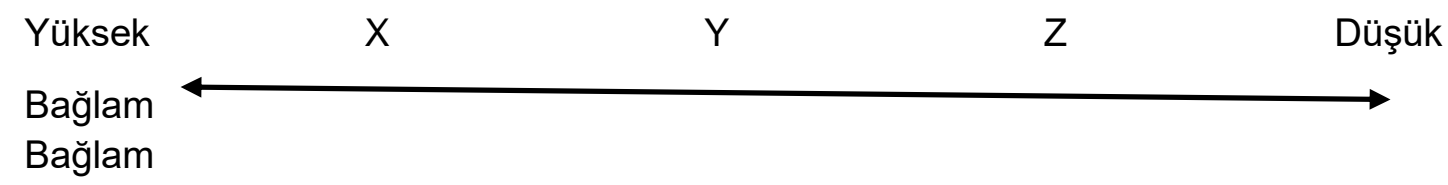

Kaynak: Robbins, Stephen P. ve Judge, Timothy A., (2013).

Yüksek bağlamlı kültürler, değişime daha kapalı olup değişim hızı yavaştır. İletişimde çok kelimeden ziyade başka araçlar sıklıkla tercih edilir. $X$ kuşağı ise $Y$ ve $Z$ kuşaklarına nazaran gelenekselliğe daha yakın durur ve otorite, emir-komuta, görev odaklılık gibi özelliklerle karakterize edilir. İletişimde daha çok imgelem ve metafor kullanarak yüksek bağlam özellikleri gösterirler (Siew, 2017:1-11). Düşük bağlamda ise esneklik, açıklık ve doğrudan iletişim söz konusudur. $Y$ ve $Z$ kuşakları yaşadıkları dönem ve taşıdıkları özellikler kapsamında esnek, özgürlükçü, açık ve sonuç odaklı özellikler ile karakterize edilirler. 
Tablo 2. Kültürel İletişim ve Kuşaklar

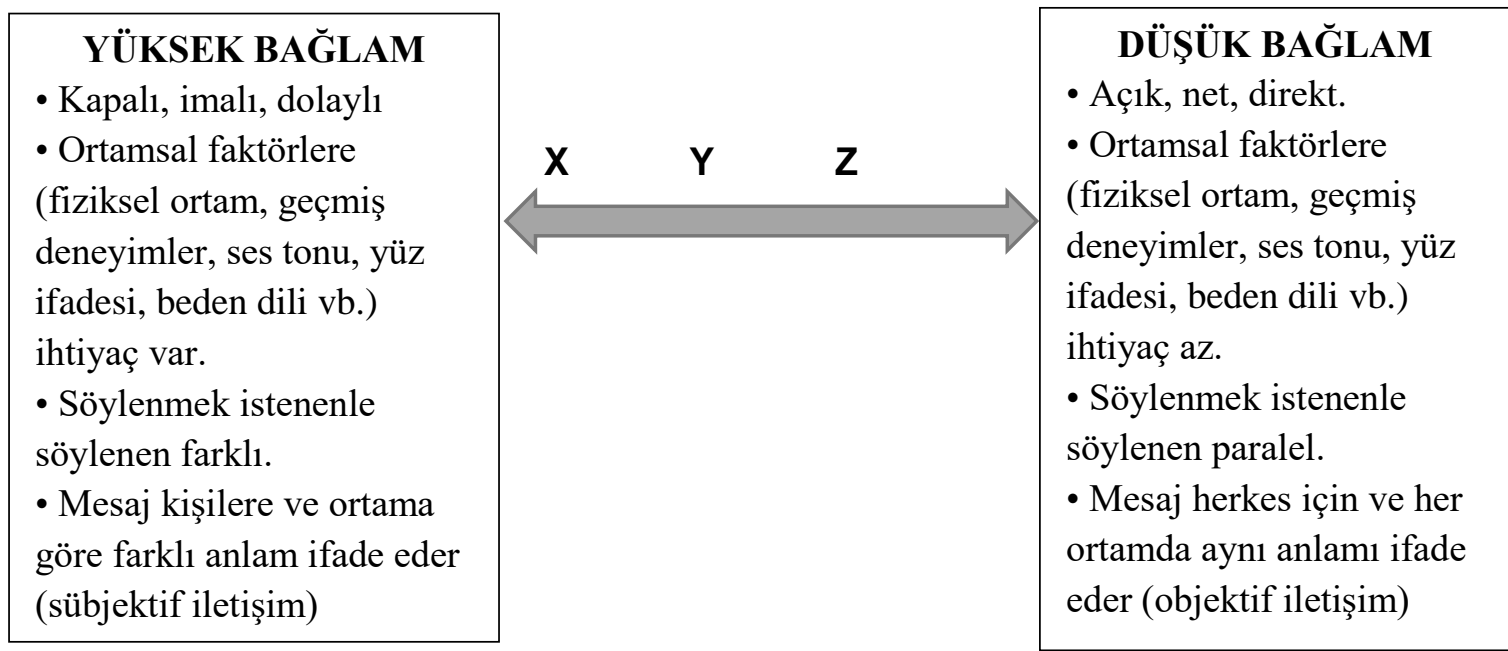

Kaynak: Erdem, Ramazan (2006).

Yüksek bağlamda sözlü iletişim tercih edilir ancak tavır ve davranışlar ekseninde anlam kazanan sözlü iletişim mesajları odak noktadadır. Toplumun arzu ettiği yanıtlar, sözlü iletişim mesajını oluşturur. Yazıdan ziyade sözlü iletişimler bağlayıcı kabul edilir. Kültürler ve iletişim nitelikleri için geliştirilen bu modelde yüksek bağlam özelliklerinin $X$ kuşağı profiline yakınsar özellikler gösterdiği çok aşikârdır. Düşük bağlamda ise yazılı iletişim tercih edilirken içeriğe yapılan vurgu ön plandadır. Yazılı metinlerdeki mesajlar dürüsttür ve sözlü iletişime çok az yer verilir. Sözlü anlaşmalar bağlayıcı kabul edilmektedir. Bu yönüyle düşük kültürel bağlam iletişim özellikleri, $Y$ ve $Z$ kuşağının taşıdığı özelliklere ve tercih ettikleri iletişim biçimlerine yakınsamaktadır:

$\checkmark$ X kuşağı liderlik biçimleri doğrudan ve komuta kontrole dayanmaktadır. Liderlik tarzı açısından bu kuşak otoriter liderliği benimsemektedir. Resmi ve yazılı iletişimi tercih etmekte ve emir komuta zincirini takip etmektedir. Günümüz koşullarına adapte olmaları zordur.

$\checkmark \times$ kuşağı üyeleri katılımcı, sorgulayıcı ve girişimci liderlik özelliğini benimsemekte olup doğrudan, yetkili, esnek, özgün, sonuç odaklı, öğrenme fırsatlarını destekleyici ve informal liderlik tarzını tercih etmektedir. İletişim tarzı açısından direkt olarak iletişim kurmaktadır. İletişim becerileri ve teknoloji bilgisi, kendilerinden bir önceki kuşak olan patlama kuşağına göre daha iyi iken, kendilerinden sonraki kuşaklara göre yani $Y$ kuşağı ve $Z$ kuşağına göre ise daha zayıftır.

$\checkmark$ Y kuşağı üyeleri mobil ya da yüz yüze görüşme dışında sanal görüşme, e-posta, sesli posta ve anlık mesajlaşma aracılığıyla da iletişim kurmaktadır. Sosyal ağlardan ve iletişimden vazgeçmeme yönleri ön plana çıkmıştır. Liderlik tarzı açısından $\mathrm{Y}$ kuşağı kendilerine ilham verecek, güvenilir, açık talimat veren, birlikte hareket edebilecekleri liderleri tercih etmektedir. 
$\checkmark$ Z kuşağı iletişim aracı olarak e-postayı tanımayıp bunun yerine sosyal ağlar ve mobil teknolojilerle iletişim kurmayı ve en yeni iletişim araçlarını kullanmayı tercih etmektedir.

$\checkmark$ Sonuç olarak bireyler her bir kuşağı daha iyi anlayarak iletişimde bulundukları kişileri kendi bakış açılarına göre yargılamaktan ziyade onları, kendilerinin bakış açısına göre yorumlama fırsatı elde edilebilir.

\section{Şekil 2. Kültür, Liderlik ve Kuşakların Siyasal İletişim Algıları}

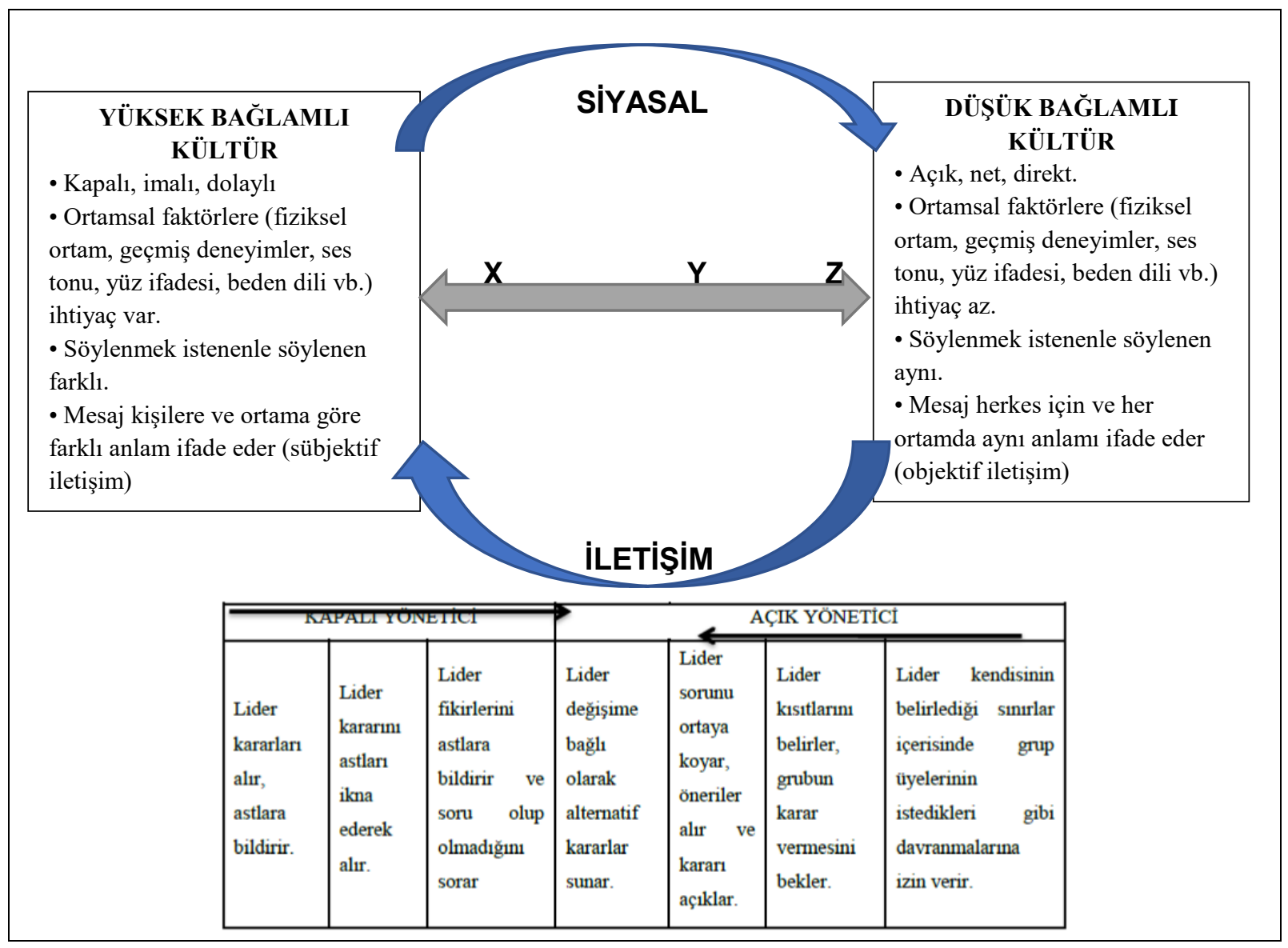

Kaynak: Gürgen, (1997).

Tabloda kuşakların kültür ve liderlik bağlamında ortaya koyduğu özellikler, siyasal iletişim çerçevesinde görülmektedir. Siyasal iletişim çalışmaları, kuşakların tablodaki iletişim tercihlerine ve liderlik anlayışlarına göre biçim almalıdır. Kitlesine hitap etmeyen siyasal iletişim muhatap bulamayarak liderlik etkisi yaratamayacaktır. Bu nedenle yukarıdaki şekilde olduğu gibi siyasal iletişim, kuşakların kültürel iletişim ve liderlik özellikleri etrafında gerçekleşmelidir. Bu konuda somut örnek vermek gerekirse Türk (2018); her seçimde yaklaşık 4,5 milyon gencin oy kullanmak için sürece katıldığını belirtmiş, bu nedenle "Hedef, strateji ve politikalar genç seçmen mantığına uygun olarak kodlanmalı." şeklinde beyanatta bulunmuştur. Bu doğrultuda Türk (2018) ayrıca: "Yeni stratejik iletişimde temel önerilerimiz var. Birincisi: Buyurucu olmayın, projelerinizi ya da önerilerinizi seçmene dikte etmeyin. En önemli şey seçmeni, yapacağınız işe dâhil edin." demiştir. Avrupa ve ABD'deki başarılı seçim sonucunun altında yatan en önemli neden seçmenin fikirlerinin alınması yoluyla sürece dâhil 
edilmesidir. İkincisi ise yeni medya ve yeni iletişim teknolojilerine uygun mesaj kodlamasıdır. Türkiye'de 51 milyon sosyal medya kullanıcısı bulunmaktadır ve Türkiye'nin yüzde 67'si sürekli olarak internet kullanabilmektedir. Ayrıca yerel seçimlere aday olacakların haritalama yoluyla seçmenlerin nerede ve ne tür beklentilere sahip olduğunu, hangi mahallede, ilçede veya kentte ne tür isteklerinin bulunduğunu, politikacılardan ne beklediklerini planlı ve programlı bir şekilde belirlemeleri gerekmektedir. Böylece doğru mesajı kodlayarak, hedef kitlelerini anlamalarına ve başarılı olmalarına büyük katkı sağlayabileceklerini belirtmiştir.

\section{Sonuç}

Çalışma kapsamında incelenen alan yazını doğrultusunda kuşakların kültür ve liderlik alanlarında oldukça belirleyici özelliklere sahip olduğu anlaşılmaktadır. Söz konusu nitelikler ise kuşaklara göre farklı siyasal iletişim algılarının oluştuğunu göstermektedir. $\mathrm{X}, \mathrm{Y}$ ve $\mathrm{Z}$ kuşaklarının sahip oldukları farklı liderlik stilleri, kültürel özellikler ve iletişim stratejilerindeki farklııklar siyasal iletişimin de tıpkı insanlar gibi değişmesini sağlamıştır. Özellikle 2010 yılından bu yana $Y$ kuşağından sayılan genç yetişkinler yetişmeye başlamış olup son beş yıldır $Y$ kuşağının farklı özelliklerinin siyasal iletişim alanında farklı yöntemlerin kullanılmasını gerekli kıldığı gözlemlenmektedir.

En temel yaklaşımla belirtilecek olursa kuşakların kültürel iletişim biçimleri birbirinden farklıdır. İletişim biçimlerinin "Yüksek Bağlam" ve "Düşük Bağlam" biçiminde ele alındığı yaklaşımda, kültürlerin iletişim şekillerinin yüksek bağlamdan düşük bağlama doğru esneklik ve değişiklikler gösterdiği ele alınmıştır. Aynı yaklaşımla kuşakların kültürel iletişim biçimleri ele alındığında ise $X$ kuşağından $Z$ kuşağına doğru gelindikçe yüksek bağlamdan düşük bağlama doğru bir seyir olduğu tespit edilmiştir. $X$ kuşağına mensup bireyler yüksek bağlam ekseninde daha kapalı iletişim stilleri, imgelem kullanma, kapalı mesaj gönderimi, sözlü ve yazılı iletişimden ziyade davranışsal tekniklerle iletişim kurma gibi özellikler göstermektedirler. Bu kültürel iletişim özellikleriyle birlikte X kuşağı, liderlik biçimleri olarak daha çok otokratik liderlik, işlemsel liderlik gibi daha hiyerarşik örgüt yapısına dayalı, klasik yönetim yaklaşımına yakınsayan, dikey şemalıdır. X kuşağı ise açık iletişim yöntemleri kullanan, imgeleme sıkça ihtiyaç hissetmeyen, sözlü ve yazılı iletişim tekniklerine başvuran esnek kültürel iletişim özellikleri ortaya koymaktadır. X kuşağı, gelenek ve otoriteyi yenilik ve özgürlükle değiştirmiş bir nesildir. Liderlik stillerinde ise daha çok demokratik liderlik stillerine eğilim gözlenirken; serbest çalışma, esnek çalışma, yatay örgüt şeması, düşük hiyerarşik yapı gibi organizasyon ortaya koydukları anlaşılmaktadır. $X$ ve $Z$ kuşağı bir bakıma birbirlerinin tam aksi gibi özellikler gösterirken $Y$ kuşağı ise bu iki nesil arasında bir geçiş dönemini kapsadığı için daha bütünleştirici ve bağ kuran nitelikler ortaya koymaktadır. Y kuşağı, geleneğin son demlerine tanıklık ederken aynı zamanda geleceğin temellerinin atıldığı dönemde yetiştiğinden hem geçmişin hem geleceğin özelliklerini taşımaktadır. $Y$ kuşağının sahip olduğu nitelikler çoğu zaman gelenekle gelecek arasında sıkışmak ve arada kalmak gibi yorumlansa da yakın gelecekte, özellikle $Y$ kuşağına mensup yetişkinlerin girişimlerinin sonuç vermeye başlamasıyla birlikte, $Y$ kuşağının niteliklerinin sıkışmak-arada kalmak değil; bütünleşik ve birleştirici bir sentezin ürünü olduğu anlaşılacaktır. $Y$ kuşağı, bir $Z$ kuşağı kadar yakından teknoloji ve değişimi takip edip yönetebilirken bir $X$ kuşağı kadar gelenek, örf, 
ananeye hâkimdir. Bu kendine has durumundan kaynaklı olarak $\mathrm{Y}$ kuşağı stratejik iletişime yatkındır, açık-kapalı iletişim biçimlerinin her ikisine de hâkimdir ve duruma göre her iki kanaldan da rahatııla iletişim mesajları iletebilir. Dönüşümcü ve etkileyici liderlik yaklaşımlarına eğilim gösterirken hiyerarşik-yatay çizgi içerisinde herhangi bir derecedeki örgüt yapısına rahatlıkla adapte olabilir.

Kuşakların bahsi geçen bu farklı kültür ve liderlik alanındaki niteliklerinden kaynaklı olarak siyasal iletişim çalışmaları da mesajların daha açık verildiği, davranışsal teknikten çok sözlü ve yazılı iletişim tekniklerini kullanan, kendi içinde tutarlı, şeffaf, hesap verebilir, istikrarlı, çift yönlü iletişime izin veren, yeniliği takip eden, birey haklarına duyarlı ve bireyselliği vurgulayan bir yöne doğru ilerlemelidir. $Y$ kuşağından başlamak üzere kuşakların siyasal iletişim algıları, kültür ve liderlik tarafından bu yönde etkilenmektedir. Siyasi liderlerin imajı, söylemleri, benimsedikleri liderlik biçimleri, temel değerleri bu yönde bir farklılık göstererek siyasi kitleye uyarlanmalıdır. Özellikle $Y$ kuşağının yetişkin çağda olduğu bu dönemlerde siyasal iletişim çift yönlü bir kanala girmiştir ve siyasal iletişimde belirgin değişimler yaşadığı görülmektedir. Türk kamuoyu sıkça siyasete taze kan gerektiğini dile getirmektedir. Siyasette taze kana intiyaç duyulmasının en önemli nedenlerinden birisi; yetişkin çağda bulunan $Y$ kuşağının kendi yaş grubundan, kendi özelliklerini taşıyan ve kendi intiyaçlarına yönelik hareket eden bir lidere duyduğu gereksinimdir. Görüldüğü gibi siyasal iletişimin gerekleri, kuşakların farklı nitelikleri tarafından tayin edilmektedir ve günümüzdeki siyasal iletişim çalışmaları kuşakların özellikleri doğrultusunda yenilenmektedir. Yine de liderlerin liderlik yaklaşımlarının yeterli gelmediği gözlemlendiğinden, siyasal iletişim çalışmalarının kuşaklara göre ortaya koyduğu yenilenmenin daha hızı ılması gerektiği anlaşılmaktadır.

Çalışmanın başında belirtildiği gibi kuşakların farklı iletişim stratejileri kullandıkları, her bir kuşağın kendine özgü kültürel dinamikleri olduğu ve liderlik yaklaşımlarının kuşaklara göre çok belirgin farklılıklar gösterdiği yapılan ayrıntılı araştırma sonucunda doğrulanmıştır. Liderlik, kültür ve iletişim gibi üç ana değişkenin kuşaklara göre farklılıklar göstermesinin siyasal iletişim algısına da yansıdığı saptanmıştır. Ancak Türkiye'deki siyasal iletişim çalışmalarında, X,Y ve Z kuşaklarının farklılık arz eden kültürel, siyasal ve kişisel beklentilerinin dikkate alınmadığı görülmektedir.

$X, Y, Z$ kuşakları arasında kültürel farklar olması ve bu farkların siyasal iletişim bağlamında da farklı algılamalara neden olmasının tespiti doğrultusunda bu kuşakların tümüne yönelik bir siyasal iletişim dili tercih etmesi gereken siyasal partiler, seçimlerde başarılı olabilmek için birbirinden ayrışan üç farklı iletişim yöntemi belirlemedirler. Özellikle Türkiye'de siyasal partilerin ve siyasal iletişim kampanyalarının bu farkları dikkate aldığını söylemek mümkün görünmemektedir. Türkiye'nin yakın geleceğinde yapılacak seçimlerde bu farklılıkları dikkate alacak partilerin seçimlerde başarılı olacağını söylemek, bir kehanet olmayacaktır. 


\section{KAYNAKLAR}

ARICAK, T. (2015). Siber Alemin Avatar Çocukları, Remzi Kitabevi, İstanbul

ALWIN, D.F., McCammon, R.J. (2007), "Rethinking Generations", Research in Human Development, C.4, S.3-4: s.219-370.

AMARAT, M., Durmuş, A., Şahin, H., \& Güleryüz, M. (2017). Kuşaklar Arasındaki Sanal Kaytarma Davranışlarının Belirlenmesi. 1. In International 11. Health And Hospital Administration Conference Kitabı (s. 93-99).

ARSLAN, Y., \& Polat, S. (2016). Eğitim Örgütlerinde Kuşaklar Arası Çatışma: Nedenleri Ve Başa Çıkma Yaklaşımları. Journal Of Kirsehir Education Faculty, C.XVII,S.1.

AYHÜN, S. E. (2013). Kuşaklar Arasındaki Farklılıklar Ve Örgütsel Yansımaları. Ekonomi Ve Yönetim Araştırmaları Dergisi, C.II, S.1: s.93-112.

AY, P. H., \& Çağlar, N. (2019). Seçmenin Siyasal Reklamlara Yaklaşımı: Şüphecilik Bakımından Kuşaklar Arası Bir İnceleme. Elektronik Sosyal Bilimler Dergisi, C.XVIII, S.70: s. 943-963.

BAKiş, O. (2017). Kuşaklar Arası Eğitim Hareketliliği: Ab-Türkiye Karşılaştırması. Finans Politik \& Ekonomik Yorumlar, C.LIV, S.634: s. 97-105.

DEMIRDAĞ, A. (2019). Ruhsal Liderliğin İş Tatmini Üzerindeki Etkisini Farklı Kuşaklar Üzerinden İnceleme, Master Tezi, Maltepe Üniversitesi, Sosyal Bilimler Enstitüsü, İstanbul.

DURSUN, M. T., \& Eriş, E. D. (2018). Konaklama İşletmelerinde Kuşaklar Bağlamında İşveren Marka Algısı ile Çalışma Yaşam Kalitesi İlişkisi. Nevşehir Hacı Bektaş Veli Üniversitesi Sbe Dergisi, C. VIII, S.1: s.160-179.

ERDEM, Ramazan (2006), "Illetişim Eğilimlerinin Yüksek-Düşük Bağlam Ayırımı ile Ölçülmesi: Türkçe Bir Ölçek Geliştirme Çalışması”, Fırat Sağlık Hizmetleri Dergisi, Cilt.ı, Sayı.2: s.17-25.

GÖKTAŞ, P. ve Çarıkçı, H. (2015). Kuşakların Siyasal İletişim Kültür ve Liderlik Açısından Değerlendirilmesi, Makü İktisadi ve İdari Bilimler Fakültesi Dergisi, C. II, S. 3: s. 7-33

GÜMÜŞ, Ö. D. (2009). Kültür, Değerler, Kişilik Ve Siyasal İdeoloji Arasındaki İlişkiler: Kültürlerarası Bir Karşılaştırma (Türkiye-Abd). Doktora Tezi, Ankara Üniversitesi, Ankara.

GÜNDOĞDU, A., \& Çelik, Ş. (2018). Türk Sermaye Piyasasında Kuşaklar Arasında Yatırımcı Ve Portföy Farklılıkları. İstanbul Üniversitesi İşletme Fakültesi Dergisi, C.XLVII, S.1:s. 46-63.

GÜRGEN, H. (1997), Örgütlerde İletişim Kalitesi, Der Yayınları, İstanbul, ss.191. 
Hall, S. (1990). Cultural İdentity And Diaspora. Https://Warwick.Ac.Uk/Fac/Arts/English/Currentstudents/Postgraduate/Masters/Module s/Asiandiaspora/Hallculturalidentityanddiaspora.Pdf, Erişim Tarihi: 13.10.2020.

KARACA, F. (2012). Toplumsal Yapıda Görülen Kuşaklar Arası Sosyal Hareketlilik: Denizli İli Örneği. Türkiye Sosyal Araştırmalar Dergisi, S.162:s.162.

KILıÇER, T. (2019). Kuşaklar Arası Etkileşimin Marka Bağlıı̆ı Üzerindeki Rolü: Takım Taraftarlığı Üzerine Bir Araştırma. Optimum: Journal Of Economics \& Management Sciences/Ekonomi Ve Yönetim Bilimleri Dergisi, C.VI, S.1.

KOCASAVAŞ, Y. (2010). Kuşaklar Arasındaki İletişimde Etkili Ve Kalıcı Dil Eğitiminin Önemi. Sakarya Üniversitesi Eğitim Fakültesi Dergisi, S.20: s. 151-160.

MENGI, Z. (2009) "Bb, X, Y ve Z Kuşakları Birbirinden Çoook Farklı", Hürriyet İK Eki, Evrim Kuran ile Röportaj, 11 Ekim 2009 Sayısı.

MENGI, Z. (2012), "Z kuşağı geliyor”, http://www.zeynepmengi.com/2012/06/zkusagigeliyor/, (30.01.2016).

MERT, G. (2020). Uluslararası İşletmelerde Etnik Köken Ve Kültürel Çeşitliliklerin Kuşaklar Bağlamında İncelenmesi. Journal Of Administrative Sciences/Yonetim Bilimleri Dergisi, C.XVIII, S.36.

MORSÜMBÜL, Ş. (2014). Değerlerin Kuşaklar Arası Değişimi: Ankara Örneği. Hacettepe Üniversitesi Sosyal Bilimler Enstitüsü Sosyoloji Anabilim Dalı, Doktora Tezi.

MÜCEVHER, M. H., Akçakanat, T., \& Demirgil, Z. (2017). İşkolikliğin Kuşaklara Göre Karşılaştırılması: Süleyman Demirel Üniversitesi Akademisyenleri Üzerine Bir Araştırma. Manas Sosyal Araştırmalar Dergisi, C.VI,S.3: s.135-155.

OKTAY, M. (2002). Politikada Halkla İlişkiler, Derin Yayınları, İstanbul.

ÖZGÜR, N. (2019). Bulgaristan Göçmeni Yetişkinlerde Travmanın Kuşaklar Arası Aktarımı İle Benlik Saygısı Arasındaki İlişkide Sosyal Desteğin Rolü, Master Tezi, ışık Üniversitesi.

ROBBiNS, Stephen P. ve Judge, Timothy A., (2013), Organizational Behaviour (Örgütsel Davranış), 14. Basımdan Çeviri, Çev: İnci Erdem Artan, Nobel Yayıncılık, Ankara.

SIEW, K. (2017). Analysis Of The Relationship Between Leadership Styles And Turnover Intention Within Small Medium Enterprise İn Malaysia. Journal Of Arts And Social Sciences, C.1, S.1: S.11.

TEKIN, M. (2015). Çalışma Yaşamında Kuşaklar Ve İşe Yönelik Tutumlarının Incelenmesi, Master Tezi, Süleyman Demirel Üniversitesi Sosyal Bilimler Enstitüsü, İsparta.

TEMIR, E. (2020). Gerontocracy vs. Generation Z: Communication Paradox of Politics in Turkey, Anadolu 4. Uluslararası Sosyal Bilimler Kongresi Özet Kitabı, s.5, Diyarbakır.

TÜRK, S.M. (2018). Basın Açıklaması http://beyazgazete.com/video/webtv/guncel1/yeni-secim-stratejisinde-sosyal-medya-nin-onemi-nevsehir-600867.html 
TWENGE, J. M. ve S. M. Campbell (2008), Generational differences in psychological traits and their impact on the workplace, Journal of Managerial Psychology, 23 (8): 862-877.

TWENGE, J.M., Campell, S.M., Hoffman B.J., Lance C.E. (2010), "Generational Differences in Work Value: Leisure and Extrinsic Value Increasing, Social and Intrinsic Value Decreasing", Journal of Management, Volume: 36, Number: 5, pp. 1117-1147.

TWENGE M. J. (2018) i-Nesli, (Çev. Okhan Gündüz) Kaknüs Yayınları, İstanbul WINTER, R. P., and Jackson, B. A. (2016). Work Values Preferences of Generation Y: Performance Relationship Insights In The Australian Public Service. The International Journal of Human Resource Management, C.XXVII, S.17.

YÖRÜKOĞLU, A. (1991). Gençlik ve Yetişkinler. B. Dikeçligil ve A. Çiğdem (Ed.). Aile Yazıları III, Birey, Kişilik ve Toplum, s.313-316. Ankara: Aile Araştırma Kurumu Başkanlığı Yayınları. 